\title{
Hacia un nuevo concepto de lo político
}

Towards a new concept of politics

\author{
Antonio Campillo
}

Universidad de Murcia campillo@um.es

DOI: http://doi.org/10.15366/bp2019.20.001 Bajo Palabra. II Época. No20. Pgs: 19-38 


\section{Resumen}

En la tradición política occidental, la política se ha identificado con la soberanía, entendida como el control coactivo de una élite gobernante sobre una población y un territorio claramente delimitados. Desde el siglo XIX, los movimientos emancipatorios han extendido la política, de manera interseccional, a todas las formas de relación social. Paralelamente, el triple proceso de urbanización, estatalización y globalización de la sociedad capitalista ha extendido el campo de lo político, de manera cosmopolita, a las diferentes escalas territoriales de interacción social, tecnológica y ecológica. Todos estos cambios nos exigen repensar el concepto de lo político y renovar la democracia en todas las esferas y escalas de la vida humana.

Palabras Clave: Politica, soberania, democracia, interseccionalidad, cosmopolitismo

\section{Abstract}

In the Western political tradition, politics has been identified with sovereignty, understood as the coercive control of a ruling elite over a clearly defined population and territory. Since the 19th century, emancipatory movements have extended the politics, in an intersectional manner, to all forms of social relations. In parallel, the triple process of urbanization, stateization and globalization of capitalist society have extended the field from the political, in an cosmopolitan manner, to the different territorial scales of social, technological and ecological interaction. All these changes require us to rethink the concept of politics and renew democracy in all spheres and scales of human life.

Keywords: Politics, Sovereignty, Democracy, Intersectionality, Cosmopolitism 


\section{Mundo, nosotros, yo}

COMENZARÉ FoRMULANDO LOS PRESUPUESTOS FILOSÓFICOS de los que voy a partir y que he desarrollado por extenso en otros textos ${ }^{1}$. El primer presupuesto concierne a las tres condiciones naturales que constituyen las bases ineludibles de nuestra existencia: nuestro propio cuerpo, la compañía de nuestros semejantes y el mundo común que compartimos con ellos y con los demás seres vivientes de la Tierra. Estas tres condiciones delimitan el horizonte de nuestra vida, pero no la predeterminan, pues tenemos cierta libertad para modelar nuestro cuerpo, la convivencia con los demás humanos y la relación con el mundo en el que habitamos. De hecho, en el curso de la historia hemos inventado los más diversos regímenes económicos, parentales y territoriales. Esto quiere decir que la humanidad no está dada y definida de una vez por todas, sino que podemos repensarla y reinventarla siempre de nuevo. En otras palabras, la condición humana es una condición constitutivamente histórico-politica. ${ }^{2}$

El segundo presupuesto concierne a la manera en que entiendo la práctica filosófica. La filosofía construye mapas simbólicos para que podamos orientarnos en nuestra relación con el mundo, con nuestros semejantes y con nosotros mismos, es decir, para que sepamos cuáles son y cuáles deberían ser las relaciones entre la Naturaleza que nos circunda y nos sustenta, la comunidad política en la que convivimos unos con otros y el cuerpo vivido que cada cual hereda y modela como su singular subjetividad ética. En resumen, la filosofía es una actividad cosmopoliética, pues trata de articular lo que los antiguos griegos llamaron el kósmos, la pólis y el éthos. ${ }^{3}$

El tercer presupuesto es un diagnóstico crítico sobre la tradición dominante de la filosofía, tal y como ha prevalecido en Occidente durante más de veinticinco siglos. Esta tradición se ha caracterizado por una pretendida despolitización del pensamiento, en la medida en que el triángulo mundo/nosotros/yo y, en particular, el régimen de convivencia política entre los humanos ha sido subordinado a la relación

\footnotetext{
${ }^{1}$ Campillo, A., Variaciones de la vida humana. Una teoría de la historia, Madrid, Akal, 2001; El concepto de lo politico en la sociedad global, Barcelona, Herder, 2008; Tierra de nadie. Cómo pensar (en) la sociedad global, Barcelona, Herder, 2015; Mundo, nosotros, yo. Ensayos cosmopoliéticos, Barcelona, Herder, 2018.

2 Campillo, A., Tierra de nadie. Cómo pensar (en) la sociedad global, op. cit., pp. 11-13.

3 Campillo, A., "Mundo, nosotros, yo. La filosofía como cosmopoliética”, en Mundo, nosotros, yo. Ensayos cosmopoliéticos, op. cit., pp. 17-51.
} 
de conocimiento verdadero entre el yo y el mundo, privilegiada como la actividad más propiamente humana y, por tanto, como la tarea distintiva de la filosofía. Durante más de veinticinco siglos, el epistemocentrismo ha sido la forma de pensamiento a la que han recurrido la mayor parte de los filósofos, teólogos y científicos occidentales para establecer la conexión entre kósmos, pólis y éthos. La dedicación metódica y desinteresada al conocimiento de lo real, entendida como una relación epistémica directa entre el yo y el mundo, ha sido considerada como la actividad más sublime del ser humano, la más eminentemente humana, por encima de la convivencia política y de la subjetividad ética. Por eso, la definición aristotélica del ser humano que ha prevalecido en Occidente no ha sido la de «animal político» (zôion politikón), sino la de «animal dotado de lenguaje» (zôion lógon échon), una expresión que Cicerón tradujo como "animal racional» (animal rationale) y que el naturalista sueco Linneo reemplazó en el siglo XVIII por la definición hoy hegemónica: homo sapiens. Sin embargo, esta tradición epistemocéntrica se funda sobre un presupuesto político: los sabios que se dedican desinteresadamente al conocimiento del mundo (sean filósofos, teólogos o científicos) deben ser también los que gobiernen a la plebe que se ocupa de las otras actividades humanas: la reproducción sexuada, en el caso de las mujeres; el sustento económico, en el caso de los trabajadores; $y$, en general, las cotidianas interacciones ético-políticas, en el caso de los ciudadanos comunes. ${ }^{4}$ En resumen, tras la despolitización epistemocéntrica de la filosofía se oculta, en realidad, una determinada epistemología política: el gobierno tecnocrático de los que saben.

A partir de estos tres presupuestos brevemente enunciados, en el presente artículo defenderé dos ideas aparentemente contrarias y en realidad complementarias.

Por un lado, la necesidad de repolitizar el pensamiento filosófico, analizando las inseparables conexiones entre el mundo, el nosotros y el yo, es decir, entre el dominio tecnocientífico de la biosfera terrestre, la regulación sociopolítica de la convivencia entre los individuos y los pueblos, y la configuración ética de la propia subjetividad, tal y como están teniendo lugar en nuestro presente, es decir, en el capitalismo globalizado del siglo XXI. En este nuevo contexto histórico, no solo es exigible que el nosotros se constituya como una comunidad política democrática, sino también que se extienda de manera «interseccional» a todas las relaciones sociales y de manera "cosmopolita» a todas las escalas territoriales de la vida humana.

Por otro lado, la necesidad de reconocer los límites de esta repolitización. Vivimos en una sociedad con una creciente capacidad tecnocientífica y sociopolítica

${ }^{4}$ Campillo, A., Tierra de nadie. Cómo pensar (en) la sociedad global, op. cit., pp. 94-100. 
para alterar la biosfera terrestre, controlar las vidas y las mentes de millones de seres humanos y remodelar la identidad física y psíquica de cada criatura singular. Sin embargo, esa inmensa trama de saberes y poderes no nos permite prever ni controlar los riesgos desencadenados por nuestras propias acciones. Al contrario, esos riesgos pueden conducirnos a un gran colapso ecológico y social, es decir, a la autodestrucción de la actual civilización planetaria. Por eso, hemos de aceptar que el mundo y el yo exceden siempre al nosotros y por tanto no pueden ser sometidos a una politización ilimitada. Hemos de reconocer los límites constitutivos de la condición humana: la Tierra en la que habitamos y de la que dependemos para construir un mundo duradero, la diversidad irreducible de nuestros semejantes, con quienes hemos de entretejer un nosotros común, y nuestro propio cuerpo vulnerable, que es el límite y la condición de nuestro yo ético.

\section{La institucionalización de las relaciones sociales}

El título De eSTe simposio, La desinstitucionalización de la política, alude a dos conceptos diferentes, el de «institución» y el de "política», cuyas relaciones son extremadamente complejas, así que trataré de clarificar qué entiendo por «institución", qué entiendo por "política» y cuáles son, en mi opinión, sus afinidades y diferencias.

Para empezar, debo recordar que la sociabilidad es una condición constitutiva de la vida humana: somos engendrados por nuestros padres, nacemos del vientre de una mujer y durante los años de infancia dependemos de nuestros cuidadores adultos para sobrevivir físicamente y para adquirir las capacidades básicas que nos caracterizan como humanos, comenzando por la capacidad de interacción social y de compromiso moral con los otros.

Ahora bien, en toda interacción social y moral entre los humanos se da una dialéctica entre el yo y el nosotros, entre la persona singular y su grupo de convivencia, es decir, entre la subjetividad ética y la comunidad política: el yo no puede sobrevivir y constituirse como un sujeto ético más que en el marco de un nosotros; pero el nosotros, a su vez, solo puede constituirse como una comunidad política más o menos cohesionada y duradera mediante la interacción entre una pluralidad de sujetos éticos singulares. Esta dialéctica entre el yo y el nosotros es el "entre» del que habla Hannah Arendt, el espacio compartido que a un tiempo separa y reúne a los miembros de una comunidad: no existe el Hombre, ni tampoco la Nación, sino la pluralidad de los seres humanos singulares que interactúan entre sí. Esta pluralidad irreducible de los sujetos éticos y la interacción entre ellos en 
el marco de una comunidad política más o menos instituida es una condición constitutiva de la vida humana ${ }^{5}$. Norbert Elias insiste también en esta dialéctica o «equilibrio» entre el yo y el nosotros para cuestionar, por un lado, el individualismo contractualista, que concibe la sociedad como el resultado de un contrato entre unos individuos presociales, y, por otro lado, el comunitarismo organicista, que la concibe como un gran organismo, es decir, como una especie de sistema viviente autorregulado en el que los individuos son meras células especializadas, funcionales e intercambiables ${ }^{6}$.

Ahora bien, las interacciones entre los humanos pueden ser efímeras e informales, sea en los encuentros cara o cara, como una pelea callejera o una cópula sexual entre dos desconocidos, sea en los movimientos sociales multitudinarios, como una huida masiva de las víctimas de una guerra civil o de una catástrofe natural. Pero también hay interacciones que son muy duraderas y que están claramente reguladas o formalizadas, como un campeonato de boxeo, una ceremonia de matrimonio, una estrategia militar o una asociación de ayuda humanitaria. En otras palabras, las interacciones humanas pueden estar más o menos institucionalizadas. Pero esta institucionalización no es un proceso histórico irreversible, pues las instituciones cambian, se transforman y a veces se deshacen o desinstitucionalizan: hay relaciones esporádicas e informales que acaban institucionalizándose, como el azaroso encuentro sexual que concluye en matrimonio o la alianza de señores feudales que da origen a un Estado soberano; pero también hay relaciones institucionalizadas que pueden llegar a desinstitucionalizarse, como un matrimonio que se divorcia o un Estado que colapsa y se desgarra en una guerra civil. Aquí me limitaré a enumerar unos cuantos rasgos básicos que caracterizan a cualquier tipo de institución social ${ }^{7}$. En mi opinión, hay cuatro rasgos que nos indican cuándo una relación social se encuentra institucionalizada:

a) La iterabilidad y previsibilidad de las acciones propias y ajenas mediante el seguimiento de reglas, sean pactadas o impuestas.

b) La punibilidad de la infracción a las reglas, desde el mero reproche verbal hasta la expulsión de la comunidad, el castigo físico, la cárcel o la muerte.

\footnotetext{
5 Arendt, H., La condición humana, Barcelona, Paidós, 1993.

${ }^{6}$ Elias, N., La sociedad de los individuos. Ensayos, ed. de M. Schröter, Barcelona, Península, 1990.

7 Sobre el concepto de «institución», remito a los dos artículos que María González Navarro y Teresa López de la Vieja publican en este monográfico de Bajo Palabra, y a los estudios ya clásicos de Max Weber, Talcot Parsons, Arnold Gehlen, Helmut Schelsky, Niklas Luhman y Thomas Luckmann. Véase, sobre todo: Weber, M., Economía y sociedad. Esbozo de sociología comprensiva, Ciudad de México, FCE, 1964; Luckmann, Th., Teoría de la acción social, Barcelona, Paidós, 1996.
} 
c) La regulación de la comunicación mediante códigos simbólicos, desde el idioma común hasta los códigos verbales y no verbales más especializados.

d) La ordenación espacio-temporal de la experiencia compartida mediante la coordinación sincrónica de las actividades sociales ${ }^{8}$ y la secuenciación diacrónica de los recuerdos y de las expectativas comunes ${ }^{9}$.

Por medio de estos cuatro procedimientos, las instituciones proporcionan a los individuos una seguridad ontológica (es decir, la supervivencia física, una identidad personal reconocida, una confianza básica en la relación con los otros, una comprensión del mundo más o menos compartida), pero también pueden socavar esa seguridad, sobre todo en el caso de los grupos sociales sometidos o excluidos (mujeres, esclavos, herejes, extranjeros, etc.). Esta es la «ambigüedad» constitutiva de toda institución: protege de los males externos, pero también puede engendrar sus propios males internos, lo que a su vez la vuelve cuestionable y susceptible de cambio o desaparición. ${ }^{10}$

Tras estas breves consideraciones sobre el concepto de «institución», voy a formular una tesis antropológica que desarrollé por extenso en mi libro Variaciones de la vida humana ${ }^{11}$. Considero que hay cuatro relaciones sociales básicas que se encuentran fuertemente institucionalizadas en todas las sociedades hasta ahora conocidas y que por tanto pueden ser consideradas como constantes antropológicas universales. La universalidad de estas cuatro instituciones sociales no es casual, sino que se debe al hecho de que regulan otras tantas condiciones naturales de la vida humana y, al regularlas, garantizan la cohesión y la perduración de las sociedades:

a) Relaciones de parentesco: regulan la reproducción sexuada, la convivencia familiar y la transmisión generacional de la experiencia cultural.

b) Relaciones económicas: regulan el sustento vital de los miembros del grupo mediante la obtención de bienes y la prestación de servicios.

c) Relaciones territoriales o comunales: regulan el control del territorio, los conflictos violentos y la adopción de acuerdos entre individuos y grupos.

\footnotetext{
8 Elias, N., Sobre el tiempo, Madrid, FCE, 2010.

9 Koselleck, R., Futuro pasado. Para una semántica de los tiempos históricos, Barcelona, Paidós, 1993.

${ }^{10}$ Bauman, Z., La cultura como praxis, Barcelona, Paidós, 2002.

11 Campillo, A., Variaciones de la vida humana. Una teoría de la historia, op. cit.
} 
d) Relaciones de comunicación simbólica: regulan la creación, codificación y transmisión de las formas simbólicas: idiomas, técnicas, saberes, ritos, etc.

Además, considero que estas cuatro relaciones o instituciones sociales básicas son irreducibles e inseparables entre sí, frente a las teorías sociales unidimensionales que privilegian una sola de ellas y le confieren un papel determinante en el proceso evolutivo de la hominización, en la estructuración interna de las sociedades y en sus procesos de transformación histórica: sea la reproducción sexual y las reglas del parentesco (a las que conceden un papel decisivo las grandes religiones patriarcales, las teorías racistas, la biología evolucionista, el psicoanálisis, la antropología estructural, el feminismo radical, etc.), el sustento económico y los modos de producción e intercambio de bienes (prioritarios para el liberalismo y el marxismo), el control del territorio y la regulación de la violencia física (considerados centrales por el realismo político y el anarquismo) o la comunicación simbólica y la creación de las diversas formas de pensamiento (privilegiadas por el epistemocentrismo y el culturalismo).

En mi opinión, ninguna sociedad humana podría mantener su cohesión interna y su perduración en el tiempo si le faltase una sola de estas cuatro instituciones básicas, así que no es posible establecer ninguna jerarquía antropológica entre ellas. Además, la diversidad espacial y temporal de las sociedades puede explicarse según el modo en que cada una ha regulado y articulado entre sí estos cuatro tipos de interacción social.

\section{Institución y política}

Y AHORA PASEmos a ANALIZAR el concepto de "política». Desde la Grecia antigua hasta hoy, este concepto ha tenido dos usos diferentes y aparentemente contrapuestos. Por un lado, en su uso restringido, el término "política» nombra una determinada institución o esfera de interacciones sociales, distinta de otras instituciones o esferas que no serían políticas sino parentales, económicas, religiosas, científicas, artísticas, etc. Por otro lado, en su uso generalizado, toda relación social -especialmente si se encuentra institucionalizada- es intrínsecamente política, de modo que los términos «institución» $\mathrm{y}$ "política» serían sinónimos. El uso restringido pretende despolitizar determinadas instituciones sociales, mientras que el uso generalizado pretende repolitizarlas y, por tanto, convertirlas en objeto de debate y de transformación. Lo más relevante es que estos dos usos no cesan de entremezclarse, sea en las disputas cotidianas o en los grandes tratados de filosofía política. Porque, a fin 
de cuentas, todo régimen de convivencia sociopolítica pretende precisamente delimitar las diversas esferas de interacción social, regularlas internamente y articularlas entre sí. Y los conflictos políticos surgen en torno a esos procesos de delimitación, regulación y articulación.

El caso de Aristóteles es prototípico ${ }^{12}$. Conviene tenerlo en cuenta, porque su Política es la obra que más influencia ha tenido en la tradición política occidental. Por un lado, el filósofo griego define al ser humano como un "animal político» (zôion politikón) y lo distingue de los demás animales sociales o gregarios por el hecho de que es un "animal dotado de lenguaje» (zôion lógon échon) y no solo de «Voz» (phöné), lo que le permite instituir leyes comunes y distinguir entre lo justo y lo injusto, y no solo expresar placer y dolor. Según esta doble definición, la convivencia política sería la dimensión constitutiva de la vida humana y atravesaría todas las esferas de interacción social. Por otro lado, la pólis -en cuanto comunidad política capaz de autodefenderse y autogobernarse- es considerada por Aristóteles como la forma de comunidad más perfecta, porque engloba y complementa a otras formas de interacción social que permanecen recluidas en la esfera privada del oíkos o hacienda familiar: la interacción parental entre hombres y mujeres para la reproducción sexual y la interacción económica entre amos y esclavos para el sustento material. La política es la dimensión constitutiva de la condición humana, pero al mismo tiempo es la esfera pública del gobierno de la ciudad (reservada a los ciudadanos varones, cabezas de familia y dueños de una hacienda, que se reconocen entre sí como «iguales»), contrapuesta a la esfera privada de la reproducción sexual y la producción económica (donde el padre y patrón gobierna como un "déspota» a familiares, esclavos y animales). Este doble uso del término "política», a un tiempo generalizado y restringido, no es un mero error de Aristóteles, sino una operación teórica y política de gran trascendencia, pues le permite excluir de la política como gobierno de la ciudad -y, por tanto, negar la plena condición humana- a las mujeres, los esclavos y los metecos (residentes extranjeros no ciudadanos), instituyendo así una jerarquía no solo entre diferentes esferas de interacción social, sino también entre diferentes categorías de seres humanos ${ }^{13}$.

Desde Aristóteles en adelante, la tradición dominante de la filosofía política occidental ha usado el término "política» de manera restringida para nombrar una determinada institución social: el gobierno coactivo o soberano que una reducida élite dominante ejerce sobre una población y un territorio más o menos

\footnotetext{
${ }^{12}$ Aristóteles, Política, ed. bilingüe griego-espańol de M. Araujo y J. Marías, Madrid, Centro de Estudios Constitucionales, $1983,2^{\mathrm{a}} \mathrm{ed}$.

${ }^{13}$ Campillo, A., "Animal político. Aristóteles, Arendt y nosotros", en Revista de Filosofia, vol. 39, no 2 (2014), pp. 169-188.
} 
delimitados, sea bajo la forma de Estado-ciudad, Estado-imperio o Estado-nación. Esto ha permitido despolitizar otras instituciones o esferas de interacción social, como las instituciones parentales, económicas y simbólicas, que han sido consideradas incuestionables, como si respondieran a un orden eterno dado por la Naturaleza o instituido por Dios. Y gracias a esta despolitización, también han sido consideradas eternas e incuestionables las jerarquías sociales entre los sexos, las clases sociales, las naciones, las etnias, etc.

En otras palabras, durante más de veinticinco siglos, la tradición política occidental ha sido una tradición patriarcal, clasista, estatal y sacerdotal, pues ha restringido la constitución del nosotros, y, con ella, el concepto mismo de lo "político" al dominio soberano de una determinada población y un determinado territorio por parte de una pequeńa élite dominante: varones, propietarios, gobernantes y sabios. Las primeras revoluciones políticas modernas del Occidente euro-atlántico (holandesa, inglesa, estadounidense y francesa) ${ }^{14}$ no rompieron con la tradición greco-latina, pues siguieron tomando como modelo ideal la politeia de Aristóteles (un "gobierno mixto» que reuniría lo mejor de la monarquía, la aristocracia y la democracia), identificada por Cicerón y Polibio con las instituciones de la respublica romana: los cónsules, el senado y los tribunos del pueblo. De hecho, la división de poderes postulada por Locke y Montesquieu no hacía sino reelaborar en términos modernos la antigua teoría del «gobierno mixto». Y los «padres fundadores» de la Constitución estadounidense se inspiraron tanto en Locke y Montesquieu como en el antiguo «gobierno mixto» o «republicano» propuesto por Aristóteles, Cicerón y Polibio. Por eso, al nuevo régimen fundado en tierras americanas no lo llamaron Democracia sino República. Incluso Thomas Jefferson, el más demócrata de los padres fundadores de Estados Unidos y el tercero de sus presidentes, siguió defendiendo el mismo ideal de ciudadano que había defendido Aristóteles dos milenios antes: un varón adulto, cabeza de una familia patriarcal y propietario de una hacienda con tierras, ganados y esclavos ${ }^{15}$.

Sin embargo, a partir del siglo XIX, comienzan a extenderse una serie de movimientos emancipatorios que se rebelan contra las diferentes formas de dominación estamental que habían perdurado en Occidente durante milenios y que las primeras revoluciones políticas modernas habían seguido perpetuando: el movimiento antiesclavista y abolicionista, los movimientos anticolonialistas e independentistas, el movimiento obrero y socialista, y, por último, el movimiento sufragista y feminista.

${ }_{14}$ Tilly, Ch., Las revoluciones europeas 1492-1992, Barcelona, Crítica, 2001.

15 Campillo, A., “Oíkos y pólis: Aristóteles, Polanyi y la economía política liberal”, en Áreas. Revista Internacional de Ciencias Sociales, no 31 (2012), pp. 27-38; Pateman, C., El contrato sexual, Barcelona y Ciudad de México, Ánthropos y UAM-Iztapalapa, 1995; Losurdo, D., Contrahistoria del liberalismo, Mataró, El Viejo Topo, 2007. 
Todos estos movimientos emancipatorios, aunque eran muy diferentes entre sí y no compartían los mismos objetivos, coincidían en reclamar la plena ciudadanía política para distintos colectivos a los que no se reconocían los «derechos del hombre y del ciudadano» proclamados solemnemente por las primeras revoluciones modernas: los esclavos negros, los pueblos colonizados, los obreros asalariados y las mujeres. Pero, al reclamar la plena ciudadanía para los colectivos excluidos de ella, los movimientos emancipatorios también repolitizaron las distintas esferas de interacción social en las que todas esas personas eran recluidas y gobernadas (la familia patriarcal, la empresa industrial, la administración colonial, la hacienda agrícola, etc.) e incluso las esferas de creación y transmisión del pensamiento simbólico (escuelas, universidades, iglesias, sociedades científicas, medios de comunicación) en las que clérigos, filósofos, científicos, literatos y maestros justificaban esas diversas formas de dominación social.

Finalmente, en la segunda mitad del siglo XX y las primeras décadas del XXI surgen nuevos movimientos sociales emancipatorios que son continuadores de los del siglo XIX, pero que al mismo tiempo plantean otro tipo de reivindicaciones, recurren a otros modos de movilización y se extienden a través de unas redes sociales cuyo alcance es cada vez más planetario y «sin fronteras», especialmente tras la aparición de Internet: los movimientos pacifistas contra las armas nucleares y contra las sucesivas guerras por la hegemonía global, desde Vietnam hasta Iraq, los movimientos antirracistas contra la segregación de los negros en Estados Unidos y contra el apartheid en Sudáfrica, las revueltas estudiantiles, las sucesivas olas del feminismo, el movimiento LGTBI, el ecologismo político, la defensa de los animales, el multiculturalismo, las ONGs humanitarias, el movimiento altermundialista, la "primavera árabe», el $15 \mathrm{M}$, etc. ${ }^{16}$

Si tenemos en cuenta todos estos procesos históricos de despolitización y de repolitización de las distintas esferas de interacción social, podemos concluir que hay una cierta dialéctica entre el uso restringido y el uso generalizado del término «política». En esa dialéctica se dan tres momentos diferentes y los teóricos de la política han tendido a privilegiar solamente uno de ellos: el momento del conflicto (Carl Schmitt) ${ }^{17}$, en el que se repolitiza una determinada institución, es decir, se la cuestiona y se reclama su transformación e incluso su abolición; el momento de la

\footnotetext{
${ }^{16}$ Castells, M., Redes de indignación y esperanza: los movimientos sociales en la era de Internet, Madrid, Alianza, 2012; Tilly, Ch., y Wood, L. J., Los movimientos sociales, 1768-2009, Barcelona, Crítica, 2009; McAdam, D., McCarthy, J. D., y Zald, M. N. (eds.), Movimientos sociales: perspectivas comparadas, Madrid, Itsmo, 1999; Tarrow, S., El poder en movimiento. Los movimientos sociales, la acción colectiva y la politica, Madrid, Alianza, 1997; Fernández Buey, F., y Riechmann, J., Redes que dan libertad. Introducción a los nuevos movimientos sociales, Barcelona, Paidós, 1994.

${ }_{17}$ Schmitt, C., El concepto de lo político, Madrid, Alianza, 2005.
} 
deliberación (Hannah Arendt) ${ }^{18}$, en el que las partes en conflicto acuerdan entre sí nuevas reglas para las viejas instituciones e incluso fundan otras instituciones que reemplazan a las anteriores; y el momento del nuevo orden ya pactado e instituido (John Rawls) ${ }^{19}$, en el que las nuevas reglas e instituciones se legitiman y se rutinizan, es decir, se cumplen de manera generalizada y, por tanto, en cierto modo se despolitizan, hasta que se produzca de nuevo su cuestionamiento y, por tanto, su repolitización. El momento del conflicto puede llegar al extremo de la guerra civil, en la que una o ambas partes traten de someter e incluso aniquilar a la otra; el momento de las reglas e instituciones estabilizadas puede llegar al extremo de la administración tecnocrática, en la que rijan relaciones de mando y obediencia aceptadas como incuestionables. Entre ambos extremos, está el momento de la contestación, el debate, la deliberación y el acuerdo, que es el momento propiamente instituyente de la convivencia sociopolítica.

Los movimientos sociales emancipatorios de los dos últimos siglos han desencadenado un proceso histórico de generalización de lo político que ha seguido una doble dirección. Por un lado, una politización horizontal de las diferentes esferas de interacción social, de modo que la política ya no se restringe hoy al gobierno del Estado, sino que afecta de manera «interseccional» ${ }^{20}$ a las relaciones entre los sexos, las clases sociales, las etnias, etc., y también afecta a las escuelas, las universidades, los centros de investigación, las empresas, los medios de comunicación, las redes sociales, etc. Por otro lado, una politización vertical de las diferentes escalas de interacción social (local, regional, estatal, continental y mundial), de modo que la política, una vez más, ya no se restringe hoy al marco del Estado soberano, sino que se extiende hacia arriba y hacia abajo, hacia lo global y hacia lo local, dada la multiplicación de actores de todo tipo que compiten, presionan o cooperan con los Estados: organismos internacionales, empresas multinacionales, medios de comunicación globales, organizaciones no gubernamentales, instituciones académicas y científicas, redes mafiosas, grupos terroristas, etc. ${ }^{21}$

Esto nos lleva a plantearnos la cuestión del uso generalizado del término "política». Si la política es una dimensión constitutiva de la vida humana, si atraviesa todas las esferas y escalas de interacción, de modo que toda institución social es en

\footnotetext{
18 Arendt, H., La condición humana, op. cit.

19 Rawls, J., Teoría de la justicia, Ciudad de México, FCE, 1995, 2a ed.

${ }^{20}$ Andersen, M. L., y Collins, P. H. (eds.), Race, Class and Gender: An Antology, Belmont (California), Wadsworth Cengage Learning, 2013, $8^{\mathrm{a}} \mathrm{ed}$.

${ }^{21}$ Held, D., y McGrew, A., Globalización/Antiglobalización. Sobre la reconstrucción del orden mundial, Barcelona, Paidós, 2003; Fraser, N., Escalas de justicia, Barcelona, Herder, 2008; Castells, M., Comunicación y poder, Madrid, Alianza, 2009.
} 
último término una institución política (desde la familia hasta la empresa, desde la escuela hasta el ejército y desde la religión hasta la ciencia), entonces hemos de averiguar en qué consiste esa dimensión transversal que es común a todas las instituciones sociales y que sin embargo no nos permite ignorar la diversidad y la especificidad irreducible de cada una de ellas. A esta cuestión podemos responder de dos maneras: desde una perspectiva macropolitica, que se centra en las instituciones constitutivas de una sociedad determinada y en su régimen estructural de funcionamiento, y desde una perspectiva micropolitica, que se centra en las relaciones intersubjetivas entre los miembros de esa sociedad y en sus reglas morales más básicas.

Desde el punto de vista macropolítico o estructural, podemos decir que la política es transversal a todas las instituciones sociales porque, a fin de cuentas, su objetivo último consiste en delimitar las distintas esferas institucionales (parentales, escolares, sanitarias, económicas, militares, científicas, gubernamentales, etc.) y sus distintas escalas territoriales (municipales, regionales, estatales, internacionales, mundiales), asignarles unas funciones determinadas, circunscribir los márgenes de su jurisdicción y determinar las articulaciones que deben establecerse entre unas y otras. En resumen, el objetivo último de la política consiste en constituir o constitucionalizar un determinado régimen de convivencia de los humanos (entre sí y con el resto de los seres del mundo). Por eso, es inevitable el entrecruzamiento entre los usos restringido y generalizado del término "política», con la consiguiente dialéctica entre los procesos de despolitización y repolitización de las diferentes esferas y escalas de interacción social.

Desde el punto vista micropolítico o intersubjetivo, la política es transversal a todas las instituciones e incluso a todas las interacciones sociales, tecnológicas y ecológicas, estén o no institucionalizadas, porque en todas ellas se dan inseparablemente relaciones de poder y de responsabilidad, hasta el punto de que la subjetividad ética de cada ser humano singular se constituye en la intersección de ese doble vínculo que lo une inseparablemente a sus semejantes y al resto de los seres del mundo ${ }^{22}$. Mientras que Michel Foucault postula la transversalidad de las relaciones de poder y de resistencia (o "gobierno de los otros» y "gobierno de sí») y su papel determinante en la constitución de la subjetividad ${ }^{23}$, Emmanuel Levinas atribuye esa transversalidad y ese papel constituyente a las relaciones de alteridad y de responsabilidad (o «interpelación del rostro del otro» $\mathrm{y}$ «hospitalidad y acogida

22 Campillo, A., "La invención del sujeto", en La invención del sujeto, Madrid, Biblioteca Nueva, 2001, pp. 219236.

${ }^{23}$ Foucault, M., Historia de la sexualidad, I. La voluntad de saber, Madrid, Siglo XXI, 1978, pp. 112-125, y Tecnologías del yo y otros textos afines, Barcelona, Paidós e ICE-UAB, 1990. 
hacia él») ${ }^{24}$, pero lo cierto es que el poder y la responsabilidad son las dos caras inseparables de la misma moneda, como han señalado Paul Ricoeur ${ }^{25}$ y Jacques Derrida ${ }^{26}$. Yo mismo he defendido en otro lugar que "toda relación social es a la vez, inseparablemente, una relación de poder y una relación de responsabilidad. Este vínculo (...) es tan estrecho e inseparable que ambas caras de la acción social suelen mantener entre sí una cierta regla de reversibilidad y de proporcionalidad (...) Sin embargo, esta regla de reversibilidad y de proporcionalidad entre el poder y la responsabilidad se encuentra socialmente modulada..." ${ }^{27}$. Pues bien, la política en su sentido generalizado y en su dimensión micropolítica o intersubjetiva consistiría en establecer esa modulación social, es decir, en el cuestionamiento, la deliberación y la adopción de acuerdos sobre el tipo de reversibilidad y de proporcionalidad que debe establecerse entre el poder y la responsabilidad en cada situación concreta, en cada relación intersubjetiva entre dos o más personas (e incluso entre los seres humanos y el resto de los seres vivientes), en cada institución social determinada y en cada escala territorial de interacción social, tecnológica y ecológica.

Entre el extremo del sujeto tiránico, que ejerce sobre los otros un poder sin límite y sin responsabilidad alguna, y el extremo opuesto del sujeto sometido, que asume ante los otros una responsabilidad sin límite y sin poder alguno, caben muchas formas de reversibilidad y de proporcionalidad entre el poder y la responsabilidad. Pero yo destacaría dos: la «responsabilidad contractual» entre personas con un poder equivalente y reversible, es decir, con iguales derechos y obligaciones, y la «responsabilidad tutelar» que las personas con más poder deben asumir hacia los seres con menos poder, es decir, hacia las criaturas más vulnerables y dependientes (niños, enfermos, ancianos, oprimidos, migrantes sin papeles, animales no humanos, etc.).

Desde las primeras revoluciones políticas modernas, el Estado soberano y colonialista, la economía capitalista mundializada y la familia patriarcal nuclear se articularon entre sí gracias a una distribución estructural o macropolítica entre el espacio de las relaciones "contractuales» (reservado a los varones propietarios europeos) y el espacio de las relaciones «tutelares» (en el que esos varones propietarios

\footnotetext{
${ }^{24}$ Levinas, E., Totalidad e infinito. Ensayo sobre la exterioridad, Salamanca, Sígueme, 1977, y De otro modo que ser o más allá de la esencia, Salamanca, Sígueme, 1987.

25 Ricoeur, P., Sí mismo como otro, Madrid, Siglo XXI, 1996.

${ }^{26}$ Derrida, J., El animal que luego estoy si(gui)endo, Madrid, Trotta, 2008; Seminario La bestia y el soberano I (2001-2002), Buenos Aires, Manantial, 2010; Seminario La bestia y el soberano II (2002-2003), Buenos Aires, Manantial, 2011.

27 Campillo, A., "Poder y responsabilidad en la sociedad global", en Campillo, A., El gran experimento. Ensayos sobre la sociedad global, Madrid, Los Libros de la Catarata, 2001, pp. 93-112. La cita corresponde a las pp. 94-95.
} 
europeos mantenían una relación de jerarquía estamental con respecto a las mujeres, los trabajadores sin propiedades y los nativos de ultramar). Por eso, precisamente, el feminismo, el socialismo y el anticolonialismo surgen para denunciar las insuficiencias y contradicciones del igualitarismo moderno, y para reclamar una reorganización del reparto estructural entre las relaciones contractuales y las relaciones tutelares.

El problema es que en la tradición política occidental, y especialmente tras las primeras revoluciones y declaraciones de derechos, la responsabilidad ético-política ha sido pensada sobre todo como una relación contractual entre ciudadanos iguales en poder, mientras que la responsabilidad tutelar ha sido minusvalorada como una relación paternalista, propia de épocas pasadas, o meramente privada, propia de las relaciones familiares y las asociaciones caritativas. Sin embargo, es preciso repensar esa jerarquía moderna entre el contrato y la tutela, problematizando el reparto social establecido entre ambos. Afortunadamente, son ya muchas las voces, sobre todo desde el feminismo y el ecologismo, que reivindican la importancia ética y política del "cuidado", no solo hacia las personas singulares y los grupos humanos más vulnerables, sino también hacia los demás seres vivos y hacia el conjunto de la biosfera terrestre. Necesitamos instituir un nuevo régimen político cosmopolita de «interdependencia» y de «ecodependencia» en el que se concilien de manera equilibrada la justicia contractual y el cuidado tutelar. ${ }^{28}$

\section{Hacia un nuevo concepto de lo político}

Toda COMUnidad política SE CONSTITUYe como tal cuando una pluralidad de seres humanos dice «nosotros» y decide actuar como tal. Ahora bien, no es tan fácil decir «nosotros» y menos aún conseguir que actúe como tal. Los dos problemas básicos son los siguientes: quién pertenece al nosotros o puede ingresar en él, es decir, el problema de sus confines demográficos y territoriales; y quién puede hablar y actuar en nombre del nosotros, es decir, el problema de su representación legítima o autorizada.

La tradición política occidental, de Platón y Aristóteles a Carl Schmitt y John Rawls, ha disociado completamente el problema de la «autoridad» legítima (es decir, monarquía, aristocracia, democracia y "gobierno mixto», en la época antigua, o bien soberanía popular y limitación constitucional de la misma, en la época

\footnotetext{
${ }^{28}$ Gilligan, C, La moral y la teoría. Psicología del desarrollo femenino, Ciudad de México, FCE, 1985; Alicia Puleo, Ecofeminismo para otro mundo posible, Madrid, Cátedra, 2011; Riechmann, J., Ética extramuros, Madrid, Ediciones UAM, 2016.
} 
moderna) y el problema de los «confines», abordado solamente por el cosmopolitismo (desde Diógenes el Cínico hasta el Kant de Para la paz perpetua). La tradición política hegemónica ha presupuesto que los confines demográficos y geográficos del nosotros han sido dados por la Naturaleza o instituidos por los dioses desde el origen de los tiempos, de modo que habría un vínculo natural, sagrado e incuestionable entre la sangre y el suelo, la etnia y la tierra. Dos mitos diferentes han servido para legitimar este vínculo: el mito griego de la autoctonía y el mito judío de la tierra prometida. La Europa moderna y colonialista recurrió al concepto romano de terra nullius y a la teoría del «descubrimiento» como bisagra conceptual para articular ambos mitos y justificar así la ocupación de los territorios de ultramar habitados por otros pueblos.

Tras la Segunda Guerra Mundial, hemos asistido a un acelerado proceso de globalización de todas las relaciones sociales, tecnológicas y ecológicas. Hoy vivimos en una sola sociedad global, cada vez más interdependiente y ecodependiente. Esta globalización de facto nos obliga a constitucionalizar una globalización de iure. La democracia ya no puede ser pensada sin el cosmpolitismo y el cosmpolitismo tampoco puede ser pensado sin la democracia. Los grandes retos a los que se enfrenta hoy la humanidad (armas nucleares, crisis ecológica global, incremento de las desigualdades sociales, grandes migraciones, redes mafiosas y terroristas, nuevas tecnologías informáticas y biológicas, etc.) no pueden ser abordados por ningún Estado en solitario, por muy poderoso que sea. En estas condiciones, el repliegue securitario en las fronteras del Estado soberano es una alternativa ilusoria y peligrosa. Hoy día, una democracia nacional es una contradicción en los términos: o es cosmopolita, o no es democracia. Los repliegues nacionalistas están provocando una "globalización amurallada». Frente a ella, necesitamos construir una democracia cosmopolita y ecológica.

En el apartado anterior he hablado de la generalización de lo político en dos direcciones. Por un lado, una dirección horizontal o «interseccional», que pondría en conexión todas las esferas de interacción social (la reproducción sexual, el sustento económico/ecológico y la comunicación simbólica), y permitiría descentrar y relativizar la esfera del control «soberano» de la violencia física y del territorio sobre el que ejerce su dominio. Por otro lado, una dirección vertical o "cosmopolita", desde lo local hasta lo global, pasando por todas las escalas de interaccion social, que también permitiría descentrar y relativizar las fronteras entre los territorios y entre las personas.

Además, he planteado que esta doble generalización de lo político nos obliga a repensar en qué consiste la política como dimensión constitutiva de la vida humana. Y he sugerido adoptar dos enfoques complementarios: uno macropolítico, 
orientado a repensar la constitucionalización de un nuevo régimen histórico-político que tenga un alcance planetario y que sea al mismo tiempo justo, democrático y sostenible; y uno micropolítico, orientado a repensar las relaciones entre el poder y la responsabilidad, y a regular de otro modo los vínculos entre la justicia contractual y el cuidado tutelar.

Terminaré este artículo regresando al principio. Para constitucionalizar un nuevo régimen histórico-político de alcance cosmopolita, hemos de reconocer los límites ontológicos de lo político, y, más concretamente, del actual proceso histórico de generalización de lo politico a todas las esferas y escalas de interacción social, tecnológica y ecológica. Los límites ontológicos de un posible nosotros cosmopolita son dos: el yo y el mundo, es decir, la singularidad irreducible de cada subjetividad ética y la potencia creadora y destructora de la biosfera terrestre. Debo hacer esta precisión porque hoy estamos asistiendo a la difusión de una utopia de politización ilimitada, que tiene una cara de burda ciencia-ficción y otra cara de cruda y delirante realidad:

a) La burda promesa "poshumanista" (a un tiempo totalitaria y tecnolátrica) de que «todo es posible», gracias a nuestros poderes/saberes sociopolíticos y tecnocientíficos: crear una nueva especie inmortal y poblar otros planetas, trascendiendo así nuestros límites corporales y terrestres. La vieja trascendencia teológica daría paso a una nueva trascendencia tecnológica. ${ }^{29}$

b) La cruda realidad del crecimiento ilimitado e incontrolado del capitalismo global, que supone una doble amenaza «biopolítica» y «ecopolítica», pues está destruyendo cada día lo que nos hace humanos: la singularidad de cada yo y la habitalidad del mundo, los dos grandes límites naturales de nuestros poderes/saberes tecno-políticos que deben ser respetados y preservados. ${ }^{30}$

Frente a esas dos utopías complementarias, delirantes y extremadamente peligrosas, debemos repensar la política no ya como un poder/saber omnipotente, omnisciente e ilimitado, sino más bien como la actividad humana más incierta, pues consiste en el cuidado cooperativo y autocontenido de las precarias condiciones que hacen posible la vida de los humanos y de los demás seres vivos. Para avanzar en esa dirección, es imprescindible la alianza entre los diversos movimientos sociales emancipatorios: el feminismo, el socialismo, el ecologismo y el pacifismo.

29 Diéguez, A., Transhumanismo. La búsqueda tecnológica del mejoramiento humano, Barcelona, Herder, 2017.

${ }^{30}$ Prats, F., Herrero, Y., y Torrego, A. (eds.) La gran encrucijada: sobre la crisis ecosocial y el cambio de ciclo histórico, Madrid, Libros en Acción, 2017, 2a ed. 


\section{ReferenCias Bibliográficas}

Andersen, M. L., y Collins, P. H. (eds.), Race, Class and Gender: An Antology, Belmont (California), Wadsworth Cengage Learning, 2013, 8a ed.

Arendt, H., La condición humana, Barcelona, Paidós, 1993.

Aristóteles, Política, ed. bilingüe griego-español de M. Araujo y J. Marías, Madrid, Centro de Estudios Constitucionales, 1983, 2a ed.

Bauman, Z., La cultura como praxis, Barcelona, Paidós, 2002.

Campillo, A., Variaciones de la vida humana. Una teoría de la historia, Madrid, Akal, 2001.

- La invención del sujeto, Madrid, Biblioteca Nueva, 2001.

- "Poder y responsabilidad en la sociedad global", en Campillo, A., El gran experimento. Ensayos sobre la sociedad global, Madrid, Los Libros de la Catarata, 2001, pp. 93-112.

- El concepto de lo político en la sociedad global, Barcelona, Herder, 2008.

— “Oikos y pólis: Aristóteles, Polanyi y la economía política liberal”, en Areas. Revista Internacional de Ciencias Sociales, no 31 (2012), pp. 27-38.

- "Animal político. Aristóteles, Arendt y nosotros", en Revista de Filosofía, vol. 39, no 2 (2014), pp. 169-188.

- Tierra de nadie. Cómo pensar (en) la sociedad global, Barcelona, Herder, 2015.

- Mundo, nosotros, yo. Ensayos cosmopoliéticos, Barcelona, Herder, 2018.

Castells, M., Comunicación y poder, Madrid, Alianza, 2009.

- Redes de indignación y esperanza: los movimientos sociales en la era de Internet, Madrid, Alianza, 2012.

Derrida, J., El animal que luego estoy si(gui)endo, Madrid, Trotta, 2008.

- Seminario La bestia y el soberano I (2001-2002), Buenos Aires, Manantial, 2010.

- Seminario La bestia y el soberano II (2002-2003), Buenos Aires, Manantial, 2011.

DiÉGuez, A., Transhumanismo. La búsqueda tecnológica del mejoramiento humano, Barcelona, Herder, 2017. 
Elias, N., Sobre el tiempo, Madrid, FCE, 2010.

- La sociedad de los individuos. Ensayos, ed. de M. Schröter, Barcelona, Península, 1990.

Fernández Buey, F., y Riechmann, J., Redes que dan libertad. Introducción a los nuevos movimientos sociales, Barcelona, Paidós, 1994.

Foucault, M., Historia de la sexualidad, I. La voluntad de saber, Madrid, Siglo XXI, 1978.

- Tecnologías del yo y otros textos afines, Barcelona, Paidós e ICE-UAB, 1990.

Fraser, N., Escalas de justicia, Barcelona, Herder, 2008.

Gilligan, C., La moral y la teoría. Psicología del desarrollo femenino, Ciudad de México, FCE, 1985.

Held, D., y McGrew, A., Globalización/Antiglobalización. Sobre la reconstrucción del orden mundial, Barcelona, Paidós, 2003.

Koselleck, R., Futuro pasado. Para una semántica de los tiempos históricos, Barcelona, Paidós, 1993.

Levinas, E., Totalidad e infinito. Ensayo sobre la exterioridad, Salamanca, Sígueme, 1977.

- De otro modo que ser o más allá de la esencia, Salamanca, Sígueme, 1987.

Losurdo, D., Contrahistoria del liberalismo, Mataró, El Viejo Topo, 2007.

Luckmann, Th., Teoría de la acción social, Barcelona, Paidós, 1996.

McAdam, D., McCarthy, J. D., y Zald, M. N. (eds.), Movimientos sociales: perspectivas comparadas, Madrid, Itsmo, 1999.

Pateman, C., El contrato sexual, Barcelona y Ciudad de México, Anthropos y UAM Iztapalapa, 1995.

Prats, F., Herrero, Y., y Torrego, A. (eds.), La gran encrucijada: sobre la crisis ecosocial y el cambio de ciclo histórico, Madrid, Libros en Acción, 2017, 2a ed.

Puleo, A., Ecofeminismo para otro mundo posible, Madrid, Cátedra, 2011.

Rawls, J., Teoría de la justicia, Ciudad de México, FCE, 1995, 2ª ed.

Riechmann, J., Ética extramuros, Madrid, Ediciones UAM, 2016. 
Ricoeur, P., Sí mismo como otro, Madrid, Siglo XXI, 1996.

Sснмiтt, C., El concepto de lo político, Madrid, Alianza, 2005.

Tilly, CH., Las revoluciones europeas, 1492-1992, Barcelona, Crítica, 2001.

Tilly, Ch., y Wood, L. J., Los movimientos sociales, 1768-2009, Barcelona, Crítica, 2009.

Weber, M., Economía y sociedad. Esbozo de sociología comprensiva, Ciudad de México, FCE, 1964.

DOI: http://doi.org/10.15366/bp2019.20.001

Bajo Palabra. II Época. No20. Pgs: 19-38 